\title{
Stimulation of melanogenesis by glycyrrhizin in B16 melanoma cells
}

\author{
Gi-Dong Jung ${ }^{1}$, Jeong-Yeh Yang ${ }^{2}$, \\ Eun-Sup Song ${ }^{1}$ and Jin-Woo Park ${ }^{2,3}$ \\ ${ }^{1}$ Department of Dermatology, Presbyterian Medical Center, \\ Chonju 560-750, Korea \\ ${ }^{2}$ Department of Biochemistry and Institute for Medical Sciences, \\ Chonbuk National University Medical School, Chonju 561-756, \\ Korea \\ ${ }^{3}$ Corresponding author: Tel, +82-63-270-3084; \\ Fax, +82-63-274-9833; E-mail, jinwoo@ @moak.chonbuk.ac.kr
}

Accepted 10 September, 2001

Abbreviations: DHICA, 5,6-dihydroxyindole-2-carboxylic acid; GA, glycyrrhetinic acid; GR, glycyrrhizin; IBMX, isobutylmethylxanthine; MTT, 3-(4,5-dimethylthiazol-2-yl)-2,5-diphenyltetrazolium bromide; PBS, phosphate-buffered saline; PKA, protein kinase A; PKC, protein kinase $C$; RT-PCR, reverse transcription-polymerase chain reaction; TCA, trichloroacetic acid; TRP, tyrosinase-related protein

\begin{abstract}
Glycyrrhizin (GR), triterpenoid saponin composed of one glycyrrhetinic acid (GA) and two glucuronic acids, is a main constituent of the hydrophilic fraction of licorice (Glycyrrhiza glabra) extracts and is known to have a wide range of pharmacological actions. In this study, we investigated the mechanism of GR effect on melanogenesis in B16 murine melanoma cells. The cellular levels of tyrosinase mRNA, protein, enzyme activities and melanin contents were increased by GR in a dose dependent manner. Expression of tyrosinase-related protein-2 (TRP-2) mRNA was also increased by GR, however, no significant change was observed on TRP-1. No cytotoxicity was observed at the effective concentration range of GR. GA showed no effect on melanogenesis at the equivalent nontoxic concentrations, indicating that glycoside structure is important in the stimulatory effect of GR on melanogenesis. These results indicate that GR-induced stimulation of melanogenesis is likely to occur through the transcriptional activation.
\end{abstract}

Keywords: melanogenesis, glycyrrhizin, tyrosinase

\section{Introduction}

The crude extract of licorice (Glycyrrhiza glabla L.) has been widely used for gastric ulcers and other diseases. Glycyrrhizin (GR) and its aglycone, glycyrrhetinic acid (GA) are the main constituents of the hydrophilic fraction of licorice extracts and are known to have a wide range of pharmacological actions including anti-inflammatory (Inoue et al., 1986), anti-allergic (Takeda et al., 1991), anti-viral (Pompei et al., 1979), anti-carcinogenic (Nishino et al., 1984), thrombin inhibitor (Francischetti et al., 1997), and anti-immune-mediated cytotoxicity (Yoshikawa et al., 1997).

Melanin synthesis is regulated by melanogenic enzymes such as tyrosinase, tyrosinase-related protein I (TRP-1), and tyrosinase-related protein 2 (TRP-2) (Hearing, 1999). Tyrosinase is a bifunctional enzyme which plays a pivotal role in the modulation of melanin production, first by catalyzing the hydroxylation of tyrosine to DOPA and secondly by catalyzing the oxidation of DOPA to DOPAquinone (Hearing and Jimenez, 1987). TRP-2, which functions as DOPAchrome tautomerase, catalyzes the rearrangement of DOPAchrome to 5,6-dihydroxyindole2-carboxylic acid (DHICA) (Yokoyama et al., 1994), and TRP-1 oxidizes DHICA to a carboxylated indole-quinone (Kobayashi et al., 1994). Both of them work at the downstream points in the melanin biosynthetic pathway.

Recently, glabridin, a main constituent of the hydrophobic fraction of licorice extracts, has been reported to have inhibitory effects on melanogenesis (Yokota et al., 1998). It is a kind of flavonoids acting as an inhibitor of tyrosinase activity. In an earlier study (Abe et al., 1987) GA inhibited the growth of B16 melanoma cells and stimulated melanogenesis. However, GR induced the similar changes requiring 20 times more concentration. Our studies showed that GR was a far more effective inducer of melanogenesis than GA at nontoxic concentration. In this study, the mechanism of GR and GA effects on melanogenesis was investigated at a cellular level using B16 murine melanoma cells.

\section{Materials and Methods}

\section{Cell Culture}

B16/F10 murine melanoma cells (kindly supplied by Professor D.G. Kim, Department of Internal Medicine, Chonbuk National University Medical School, Chonju, Korea) were cultured in DMEM containing $10 \%$ fetal bovine serum, $100 \mathrm{U} / \mathrm{ml}$ penicillin, $0.1 \mathrm{mg} / \mathrm{ml}$ streptomycin, and $0.25 \mu \mathrm{g} / \mathrm{ml}$ amphotericin $\mathrm{B}$ at $37^{\circ} \mathrm{C}$ in a humidified $95 \%$ air $/ 5 \% \mathrm{CO}_{2}$ atmosphere. Cells were seeded on 6-well plates and drug treatment began $24 \mathrm{~h}$ 
after seeding. GR was obtained from Sigma Chemical Co. (St. Louis, U.S.A.) and GA from Aldrich Chemical Co. (Milwaukee, U.S.A.). The cells were harvested three days later and the melanin contents and tyrosinase activities were determined in triplicate for each treatment (Ando et al., 1998).

\section{Melanin content measurement}

Melanin contents of cultured B16/F10 cells were measured according to the method of Kim et al. (1998) with a slight modification. Cells were washed twice with phosphate-buffered saline (PBS) and lysed with $20 \mathrm{mM}$ Tris- $0.1 \%$ Triton $\mathrm{X}-100(\mathrm{pH} 7.5)$. Cell lysate was precipitated with same amount of $20 \%$ trichloroacetic acid (TCA). After washing twice with $10 \%$ TCA, pellets were treated with ethyl alcohol : diethyl ether $(3: 1)$ and diethyl ether successively. Samples were air-dried, dissolved in $1 \mathrm{ml}$ of $0.85 \mathrm{M} \mathrm{KOH}$, and boiled for $15 \mathrm{~min}$. After cooling, absorbance was measured with a spectrophotometer at $400 \mathrm{~nm}$. The amount of cellular melanin was corrected by the protein contents of the samples. Protein concentration was determined by the method of Bradford (Bradford, 1976).

\section{Assay of tyrosinase activity}

Tyrosinase activity was assayed as DOPA oxidase activity using a modified method described by Lerch (Lerch, 1987). Cells were washed twice with PBS and lysed with $20 \mathrm{mM}$ Tris- $0.1 \%$ Triton $\mathrm{X}-100(\mathrm{pH} 7.5)$. Tyrosinase activity was analyzed spectrophotometrically by following the oxidation of DOPA to DOPAchrome at $475 \mathrm{~nm}$. The reaction mixture containing $100 \mu \mathrm{l}$ of freshly prepared substrate solution [0.1\% L-DOPA in $0.1 \mathrm{M}$ sodium phosphate $(\mathrm{pH} \mathrm{6.0)]} \mathrm{and} 50 \mu$ l of enzyme solution was incubated at $37^{\circ} \mathrm{C}$. The absorbance change was measured during the first $10 \mathrm{~min}$ of the reaction while the increase of the absorbance was linear, and corrections for auto-oxidation of L-DOPA in controls were made. The specific activity of tyrosinase in control cells was $0.37 \pm 0.01 \mathrm{mmol}$ L-DOPA oxidized $/ \mathrm{min} / \mathrm{mg}$ protein and activities were expressed as percentage of control cells.

\section{MTT assay}

General viability of cultured cells was determined by reduction of 3-(4,5-dimethylthiazol-2-yl)-2,5-diphenyltetrazolium bromide (MTT) to formazan (Mosmann, 1983). After treatment, cells were washed twice with PBS. MTT $(100 \mu \mathrm{g} / 0.1 \mathrm{ml}$ PBS$)$ was added to each well. Cells were incubated at $37^{\circ} \mathrm{C}$ for $1 \mathrm{~h}$, and dimethyl sulfoxide (100 $\mu$ ) was added to dissolve the formazan crystals. The absorbance was then measured at $570 \mathrm{~nm}$ with a spectrophotometer (Spectra MAX PLUS, Molecular Devices, Sunnyvale, U.S.A.).

\section{Western blotting}

Cells were homogenized in $100 \mu$ of ice-cold lysis buffer (20 mM HEPES; pH 7.2, 1\% Triton X-100, 10\% glycerol, $1 \mathrm{mM}$ phenylmethylsulfonyl fluoride, $10 \mu \mathrm{g} / \mathrm{ml}$ leupeptin, $10 \mu \mathrm{g} / \mathrm{ml}$ aprotinin). The homogenates containing $20 \mu \mathrm{g}$ of protein were separated by SDS-PAGE with $10 \%$ resolving and $3 \%$ acrylamide stacking gel (Laemmli, 1970), and transferred to nitrocellulose sheets (Schleicher \& Schuell, Germany) in a Western blot apparatus (BioRad, Hercules, U.S.A.) run at $50 \mathrm{~V}$ for $2 \mathrm{~h}$. The nitrocellulose paper was blocked with $2 \%$ bovine serum albumin and then incubated for $4 \mathrm{~h}$ with $1 \mu \mathrm{g} / \mathrm{ml}$ goat anti-murine tyrosinase IgG (Santa-Cruz Biotechnology Inc., Santa-Cruz, U.S.A.). The binding of antibody was detected with anti-goat IgG conjugated with alkaline phosphatase (Sigma, St. Louis, U.S.A.). Immunoblots were developed using a BCIP/NBT solution (Pierce, Rockford, U.S.A.).

\section{Reverse Transcription-Polymerase Chain Reaction (RT-PCR)}

Total cellular RNA was prepared using Tri-zol solution (Gibco-BRL, Paisley, UK) according to the manufacturer's instructions. After the preparation of cDNA with oligo $d(T)^{16}$ as a reverse transcriptase primer from the extracted RNA, amplification with PCR was performed using GeneAmp kit (Perkin Elmer, Foster City, U.S.A.) according to the manufacturer's manual. The oligonucleotide primers used for PCR are as follows: tyrosinase upstream 5'-GGC CAG CTT TCA GGC AGA GGT-3'; downstream 5'-TGG TGC TTC ATG GGC AAA ATC-3': TRP-1 upstream 5'-GCT GCA GGA GCC TTC TTT CTC-3'; downstream 5'-AAG ACG CTG CAC TGC TGG TCT-3': TRP-2 upstream 5'-GGA TGA CCG TGA GCA ATG GCC-3'; downstream 5'-CGG TTG TGA CCA ATG GGT GCC-3': actin upstream 5'-TGG AAT CCT GTG GCA TCC ATG AAA C-3'; downstream 5'-TAA AAC GCA GCT CAG TAA CAG TCC G-3'. CDNA amplification used the product of about $1 \mu \mathrm{g}$ of total RNA. The reaction was cycled 20 times through $60 \mathrm{~s}$ at $94^{\circ} \mathrm{C}, 60 \mathrm{~s}$ at $56^{\circ} \mathrm{C}$, and $60 \mathrm{~s}$ at $72^{\circ} \mathrm{C}$. Fifty percent of reaction mixture was analyzed by electrophoresis on $1.5 \%$ agarose gels and stained by ethidium bromide. In order to check the reproducibility of the results, each experiment was carried out more than three times.

\section{Results}

To investigate the effect of GR on melanogenesis, B16/ F10 murine melanoma cells were incubated with various concentrations of GR for $72 \mathrm{~h}$. The cellular content of melanin was increased by GR in a dose-dependent manner (Figure 1). At the concentration of $0.5 \mathrm{mM}$, the 


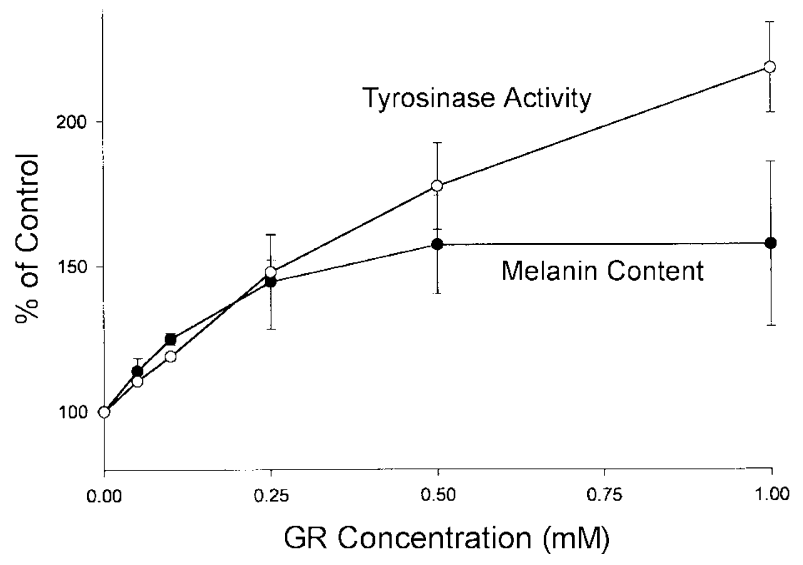

Figure 1. Effect of GR on the melanin content and tyrosinase activity. After incubation of B16 murine melanoma cells with various concentrations of GR for $72 \mathrm{~h}$, melanin contents and tyrosinase activities were determined as described in "Materials and Methods". Data are expressed as a percentage of control and are mean $\pm \mathrm{SE}$ of three separate experiments.

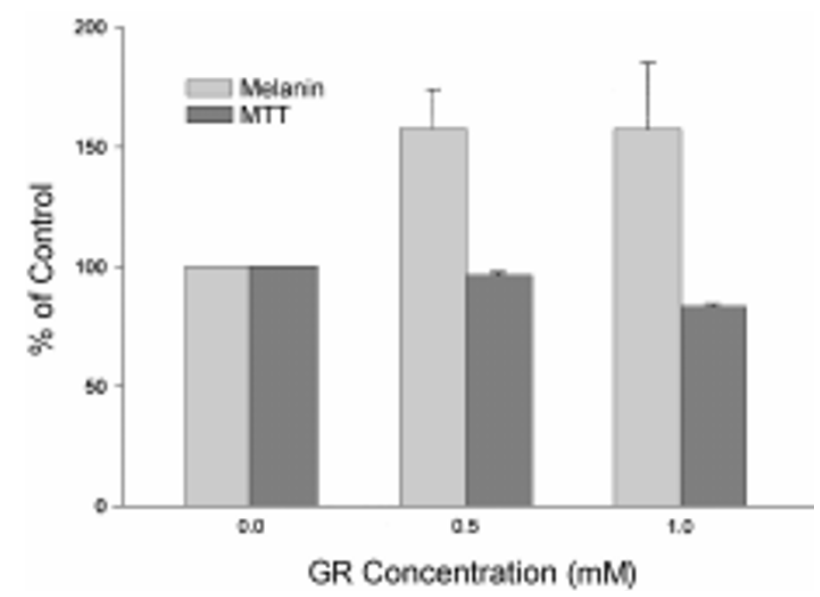

Figure 2. Effect of GR on the melanin content and cytotoxicity. After incubation of B16 murine melanoma cells with various concentrations of GR for $72 \mathrm{~h}$, determination of melanin contents and MTT assay were performed. Data are expressed as a percentage of control and are mean \pm SE of three separate experiments.

cellular melanin content reached nearly to plateau, about $160 \%$ of control cells. The cellular tyrosinase activity was also increased dose-dependently by GR, reaching to $220 \%$ of control cells at the concentration of $1 \mathrm{mM}$ (Figure 1). No cytotoxicity was observed with less than $0.5 \mathrm{mM}$ of GR. Even at $1 \mathrm{mM}$, only $15 \%$ decrease in cell number estimated by MTT assay was observed (Figure 2).

GR has the structure of triterpenoid saponin composed of one GA and two glucuronic acids. To determine whether the stimulatory effect of GR on melanogenesis was due to the component of GA, cells were incubated with GA and its effect was investigated. As shown in Figure 3, GA showed no effect on the cellular melanin content and tyrosinase activity till $10 \mu \mathrm{M}$. Rather, it

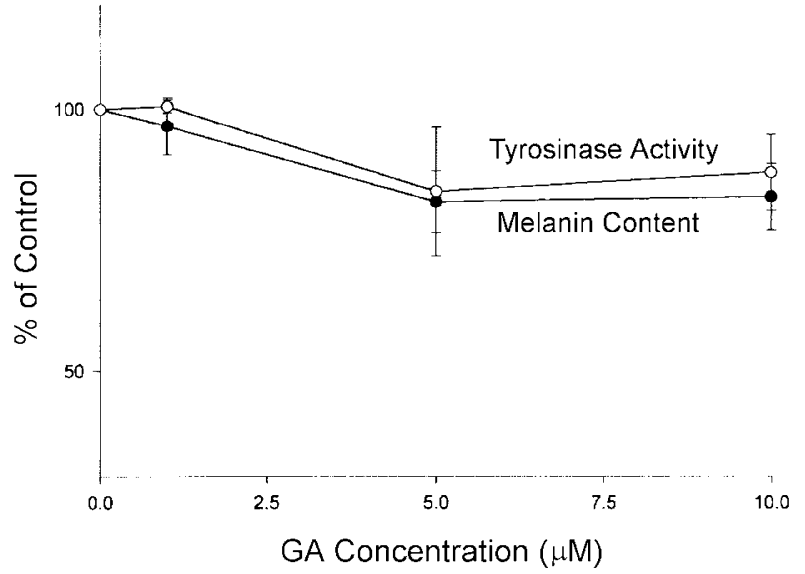

Figure 3. Effect of GA on the melanin content and tyrosinase activity. After incubation of $B 16$ murine melanoma cells with various concentrations of $G A$ for $72 \mathrm{~h}$, melanin contents and tyrosinase activities were determined. Data are expressed as a percentage of control and are mean \pm SE of three separate experiments.

1

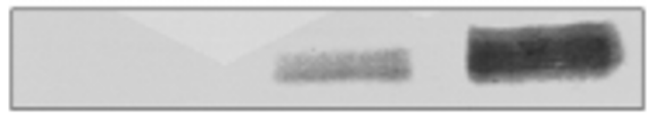

Figure 4. Western blotting of tyrosinase. B16 murine melanoma cells were incubated with none (lane 1), $1 \mathrm{mM}$ GR (lane 2) or $0.1 \mathrm{mM}$ IBMX (lane 3) for $72 \mathrm{~h}$. After the lysis of cells, proteins were separated on SDS-PAGE and transferred to nitrocellulose paper. Immunoblotting with murine tyrosinase antibody was performed.

showed a tendency of suppression for melanogenesis. Over the concentration of $10 \mu \mathrm{M}$, it was impossible to assay due to strong cytotoxicity.

The amount of tyrosinase protein in the cell was visualized by Western blotting. When cells were treated with $1 \mathrm{mM}$ of GR for $72 \mathrm{~h}$, significant increase of tyrosinase protein was observed (Figure 4, lane 2). As a positive control, isobutylmethylxanthine (IBMX) was used to induce the tyrosinase expression (Figure 4, lane 3).

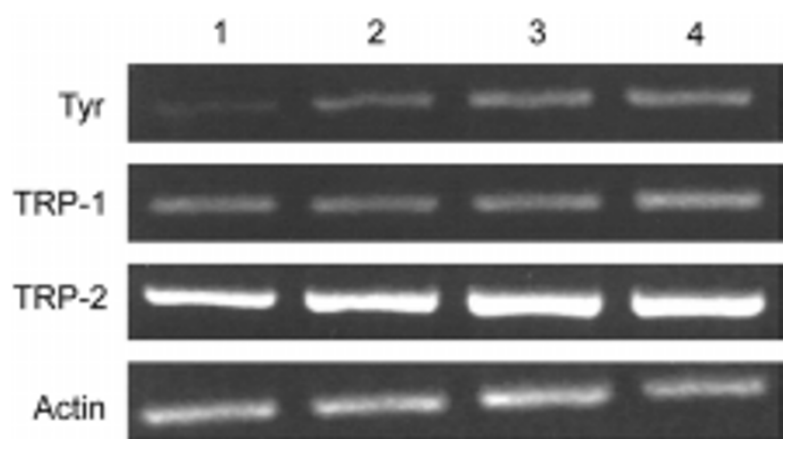

Figure 5. RT-PCR profiles of tyrosinase, TRP-1 and TRP-2. B16 murine melanoma cells were incubated with none (lane 1), $0.5 \mathrm{mM}$ GR (lane 2), 1 mM GR (lane 3) or $0.1 \mathrm{mM} \mathrm{IBMX} \mathrm{(lane} \mathrm{4)} \mathrm{for} 72 \mathrm{~h}$. RT-PCR for tyrosinase, TRP-1 and TRP-2 gene was performed on RNA extracts. 
The expressions of mRNA for tyrosinase, TRP-1 and -2 were investigated through the RT-PCR. Cells were treated with 0.5 and $1 \mathrm{mM}$ of $\mathrm{GR}$ for $72 \mathrm{~h}$ and the total cellular RNA was extracted. Specific mRNAs were amplified, after reverse transcription, with PCR using specific primers for tyrosinase, TRP-1 and -2. As shown in Figure 5, mRNAs of tyrosinase and TRP-2 were increased by the treatment of GR. No significant change was observed on TRP-1. All of the three components were increased by IBMX (Figure 5, lane 4). These results indicate that GR-induced stimulation of melanogenesis occurs at the transcriptional level.

\section{Discussion}

In this study, we observed that GR stimulates the melanogenesis in B16 murine melanoma cells, and GRinduced stimulation occurs through the increased expression of tyrosinase and TRP-2 at the transcriptional level.

The hydrophobic fraction of licorice extracts, which contains various flavonoids, has been known to have the inhibitory effects on melanogenesis possibly due to its inhibition of tyrosinase activity (Yokota et al., 1998). As shown in the results, it was impossible to assess the effect of GA on melanogenesis due to its high cytotoxicity at the concentrations over $10 \mu \mathrm{M}$. Even at the non-cytotoxic levels, GA showed nearly no or slight suppressive effect on melanogenesis in contrast to the previous report of Abe et al. (1987). The difference of drug preparation might be one of the possible explanations. GR becomes hydrophilic by two attached glucuronic acids to the hydrophobic core, GA. GR has stimulatory effect indicating that glycoside structure of GR is important in the stimulation on melanogenesis. GR showed no direct effect on tyrosinase activity (data not shown).

Melanin is a unique pigmented biopolymer synthesized by specialized cells known as melanocytes, dendritic cells that exist as relatively minor populations in the skin, hair, eyes and other locations. Melanin has a number of important functions, ranging from its role in the determination of phenotypic appearance, to protective coloration, to balance and auditory processing, to absorption of toxic drugs and chemicals, and to neurologic development during embryogenesis (Hearing, 1998).

Melanogenesis itself is a complex process. In fact, the number of genes involved in regulating mammalian pigmentation is quite large, and at least 80 genetic loci are known to regulate melanogenesis either directly or indirectly (Hearing, 1999). Mutations of these genes have been shown to be associated with different pigmentary diseases, including various forms of ocular and oculocutneous albinism, piebaldism, Hirschsprung's disease, and Waardenberg's syndrome (Hearing, 1999).
Among those, tyrosinase gene family had been known to play an important role in the regulation of melanogenesis (Pawelek and Chakraborty, 1998). Tyrosinase gene family consists of tyrosinase, TRP-1 and TRP-2. They are glycoproteins embedded in the melanosome membrane that share $70-80 \%$ nucleotide sequence homology with $30-40 \%$ amino acid identity, and share common functional motifs such as epidermal growth factor receptor and copper binding sites (del Marmol and Beermann, 1996).

GR increased the gene expression and protein contents of tyrosinase. Expression of TRP-2, but not TRP-1, was also increased by GR. Recent works on molecular mechanisms regulating pigmentation suggest that cAMP and protein kinase $\mathrm{C}$ (PKC) are the two major intracellular signaling molecules critical for pigmentation (Busca and Ballotti, 2000). Extracellular signals increase cAMP levels, activating protein kinase A (PKA). PKA then presumably alters the transcription rate of key genes including tyrosinase. Inactive PKC may also be activated by extracellular signal. Active PKC then phosphorylates tyrosinase, leading to its activation (Park and Gilchrest, 1999). Recently, there are reports that cGMP signal transduction pathway stimulates melanogenesis (Romero-Graillet et al., 1996; Romero-Graillet et al., 1997). The signal transduction pathway in GR-mediated stimulation of melanogenesis requires further study.

Stimulatory effect of GR on melanogenesis might be applied to various conditions of hypopigmentation-related disorders as an adjunctive therapy. It would also be possible to produce effective agents available for such purpose by modification of chemical structure of GR.

\section{References}

Abe $\mathrm{H}$, Ohya N, Yamamoto KF, Shibuya T, Arichi S, Odashima S. Effects of glycyrrhizin and glycyrrhetinic acid on growth and melanogenesis in cultured B16 melanoma cells. Eur J Cancer Clin Oncol 1987;23:1549-55

Ando H, Ryu A, Hashimoto A, Oka M, Ichihashi M. Linoleic acid and alpha-linolenic acid lightens ultraviolet-induced hyperpigmentation of the skin. Arch. Dermatol Res 1998;290:37581

Bradford MM. A rapid and sensitive method for the quantitation of microgram quantities of protein utilizing the principle of protein-dye binding. Anal Biochem 1976;72:24854

Busca R, Ballotti R. Cyclic AMP, a key messenger in the regulation of skin pigmentation. Pigment Cell Res 2000;13:6069

del Marmol V, Beermann F. Tyrosinase and related proteins in mammalian pigmentation. FEBS Lett 1996;381:165-68

Francischetti IM, Monteiro RQ, Guimaraes JA, Francischetti B. Identification of glycyrrhizin as a thrombin inhibitor. Bio- 
chem Biophys Res Commun 1997;235:259-63

Hearing VJ, Jimenez M. Mammalian tyrosinase-the critical regulatory control point in melanocyte pigmentation. Int $\mathrm{J}$ Biochem 1987;19:1141-47

Hearing VJ. Regulation of melanin formation. In The pigmentary system: physiology and pathophysiology (Nordlund, J. J., Boissy, R. E., Hearing, V. J., King, R. A. and Ortonne, J.P., eds.), 1998, pp.423-438, Oxford University Press, Inc., New York

Hearing VJ. Biochemical control of melanogenesis and melanosomal organization. J Investig Dermatol Symp Proc 1999;4:24-28

Inoue $\mathrm{H}$, Saito $\mathrm{H}$, Koshihara $\mathrm{Y}$, Murota $\mathrm{S}$. Inhibitory effect of glycyrrhetinic acid derivatives on lipoxygenase and prostaglandin synthetase. Chem Pharm Bull 1986;34:897-901

Kim DG, Kim HY, Kim MY, Lee MY, You KR. Lincomycin abrogates dexamethasone-enhanced melanogenesis in B16 melanoma cells. Pigment Cell Res 1998;11:143-50

Kobayashi T, Urabe K, Winder A, Jimenez-Cervantes C, Imokawa G, Brewington T, Solano F, Garcia-Borron JC, Hearing VJ. Tyrosinase related protein 1 (TRP1) functions as a DHICA oxidase in melanin biosynthesis. Embo J 1994;13: 5818-25

Laemmli UK. Cleavage of structural proteins during the assembly of the head of bacteriophage T4. Nature 1970;227: 680-85

Lerch K. Monophenol monooxygenase from Neurospora crassa. Methods Enzymol 1987;142:165-69

Mosmann T. Rapid colorimetric assay for cellular growth and survival: application to proliferation and cytotoxicity assays. $J$ Immunol Methods 1983;65:55-63

Nishino H, Kitagawa K, Iwashima A. Antitumor-promoting activity of glycyrrhetic acid in mouse skin tumor formation induced by 7,12-dimethylbenz[a]anthracene plus teleocidin. Carcinogenesis 1984;5:1529-30
Park HY, Gilchrest BA. Signaling pathways mediating melanogenesis. Cell Mol Biol 1999;45:919-30

Pawelek JM, Chakraborty AK. The enzymology of melanogenesis. In The pigmentary system: physiology and pathophysiology (Nordlund, J. J., Boissy, R. E., Hearing, V. J., King, R. A. and Ortonne, J.-P., eds.), 1998, pp.391-400, Oxford University Press, Inc., New York

Pompei R, Flore O, Marccialis MA, Pani A, Loddo B. Glycyrrhizic acid inhibits virus growth and inactivates virus particles. Nature 1979;281:689-90

Romero-Graillet C, Aberdam E, Biagoli N, Massabni W, Ortonne JP, Ballotti R. Ultraviolet B radiation acts through the nitric oxide and cGMP signal transduction pathway to stimulate melanogenesis in human melanocytes. J Biol Chem 1996;271:28052-56

Romero-Graillet C, Aberdam E, Clement M, Ortonne JP, Ballotti R. Nitric oxide produced by ultraviolet-irradiated keratinocytes stimulates melanogenesis. J Clin Invest 1997; 99:635-42

Takeda H, Ohta K, Niki H, Matsumoto Y, Tanaka K, Machimura H, Yagame M, Inoue W, Endoh M, Kaneshige $H$. Eosinophilic peritonitis responding to treatment with glycyrrhizin. Tokai J Exp Clin Med 1991;16:183-86

Yokota T, Nishio H, Kubota Y, Mizoguchi M. The inhibitory effect of glabridin from licorice extracts on melanogenesis and inflammation. Pigment Cell Res 1998;11:355-61

Yokoyama K, Yasumoto K, Suzuki H, Shibahara S. Cloning of the human DOPAchrome tautomerase/tyrosinase-related protein 2 gene and identification of two regulatory regions required for its pigment cell-specific expression. J Biol Chem 1994;269:27080-87

Yoshikawa M, Matsui Y, Kawamoto H, Umemoto N, Oku K, Koizumi M, Yamao J, Kuriyama S, Nakano H, Hozumi N, Ishizaka S, Fukui $\mathrm{H}$. Effects of glycyrrhizin on immunemediated cytotoxicity. J Gastroenterol Hepatol 1997;12:24348 